\title{
Estado actual de las investigaciones en la localidad arqueológica Laguna de los Gansos (Diamante, Entre Ríos)
}

1941-2016 75 AÑOS

RMA

Arqueología

\section{Current research at Laguna de los Gansos archaeological locality (Diamante, Entre Ríos)}

Mariano Bonomo*, Gustavo Politis**, Carolina Silva*, Laura Bastourre*, Ma. Agustina Ramos van Raap*, Carola Castiñeira Latorre***, Clara Scabuzzo* y Eduardo Apolinaire*

*CONICET, División Arqueología, Facultad de Ciencias Naturales y Museo, Universidad Nacional de La Plata, La Plata, Argentina. E-mails: mbonomo@fcnym.unlp.edu.ar, karitosilva@gmail.com, laurabastourre@yahoo.com.ar, magustina_rvr@hotmail.com, clarascabuzzo@hotmail.com, eapolinaire@gmail.com

${ }^{* * C O N I C E T}$, INCUAPA, Facultad de Ciencias Sociales, Universidad del Centro de la Provincia de Buenos Aires, Olavarría, Argentina. División Arqueología, Facultad de Ciencias Naturales y Museo, Universidad Nacional de La Plata, La Plata, Argentina. E-mail: gpolitis@museo.fcnym.unlp.edu.ar ${ }^{* * * *}$ CONICET, División Mineralogía y Petrología,Facultad de Ciencias Naturales y Museo, Universidad Nacional de La Plata, La Plata, Argentina. E-mail: carolacl2004@yahoo.com

\begin{abstract}
Resumen
Las investigaciones arqueológicas desarrolladas en los últimos años en el Delta Superior del Paraná buscan ampliar el conocimiento sobre la arqueología regional, entendida como historia indígena de larga duración. En este artículo se presentan los resultados de los análisis arqueofaunísticos, cerámicos, bioarqueológicos, geoarqueológicos y radiocarbónicos realizados en la localidad arqueológica Laguna de los Gansos. En ésta se excavaron dos sitios (LDLG1 y LDLG2) emplazados a lo largo de un albardón al Oeste de la laguna homónima. En LDLG1 se hallaron abundantes fragmentos cerámicos lisos y decorados (incluyendo modelados zoomorfos) y material arqueofaunistico caracterizado por la elevada frecuencia de coipo, carpincho y ciervo de los pantanos. Este sitio representa una sucesión de ocupaciones cortas sobre un albardón que ocurrieron entre ca. 1200 y 1800 años ${ }^{14} \mathrm{C} A P$. En LDLG2 se recuperaron restos humanos (en entierros primario y secundario) datados entre 570 y 590 años ${ }^{14} \mathrm{C} A P$, junto a material cerámico, carbón y restos arqueofaunísticos. En suma, la localidad Laguna de los Gansos muestra una profunda historia de uso de las islas fluviales del Paraná y sus recursos acuáticos. Asimismo, su cronología temprana permite abordar la génesis y dispersión de Goya-Malabrigo a la luz de los nuevos modelos sobre etnogénesis.
\end{abstract}

Palabras clave: Delta Superior del Paraná; Holoceno tardío; Goya-Malabrigo; sitio somero.

\begin{abstract}
Archaeological research recently carried out at the Upper Delta of the Paraná River is aimed to widen our knowledge about regional archaeology, understood as long-term indigenous history. In this paper the results of the zooarchaeological, bioarchaeological, geoarchaeological, pottery and radiocarbon analyses performed at Laguna de Los Gansos archaeological locality are presented. Two sites (LDLG1 and LDLG2) emplaced along a levee, west of Los Gansos lagoon, were excavated. At LDLG1 many potsherds (including zoomorphic appendages) and archaeofaunal remains characterized by high frequencies of coypu, capybara and marsh deer were found. This site represents a set of successive brief occupations of a levee occupied between1200 and $1800{ }^{14} \mathrm{C}$ years BP. At LDLG2 human remains (primary and secondary inhumations) dated between 570 and $590{ }^{14} \mathrm{C}$ years $B P$ were found associated with potsherds, charcoal and archaeofaunal remains. In sum, Laguna de Los Gansos locality exhibits a deep history of use of the Parana fluvial islands and its aquatic resources. Furthermore, its early chronology enables the discussion of the origin and spread of Goya-Malabrigo in the light of recent ethnogenesis models.
\end{abstract}

Keywords: Upper Delta of the Paraná River; Late Holocene; Goya-Malabrigo; shallow site.

El Delta del Paraná es uno de los deltas más grandes de América del Sur, con una extensión de $15.000 \mathrm{~km}^{2}$. Se encuentra entre los $32^{\circ}$ y $34^{\circ} 30^{\prime}$ de Lat. S, en la porción terminal de la cuenca del río homónimo. Es un ecosistema muy productivo y particular ya que a pesar de estar en una latitud de clima templado, contiene una fauna y una flora con marcados elementos subtropicales. Esta área fue una de las primeras en ser investigadas arqueológicamente 
en la Argentina (Lista 1878; Torres 1907; Zeballos y Pico 1878) e inclusive fue mencionada en una de las primeras obras de síntesis sobre la arqueología de América del Sur (Joyce 1912). Desde entonces, el Delta del Paraná fue una unidad de análisis espacial en la arqueología americana (Lafon 1972; Lothrop 1932; Serrano 1972; Willey 1971) y ha sido investigada con diferente intensidad y desde variados enfoques teóricos (Bonomo et al. 2011a; Caggiano 1984; Lafon 1972; Loponte 2008).

Durante más de un siglo de investigación casi continua, se fue definiendo una entidad arqueológica con rasgos bastante claros denominada Goya-Malabrigo (González 1977) o también conocida previamente como "Ribereños plásticos" (Serrano 1972). Esta entidad fue caracterizada por la ocupación de las islas y la planicie de inundación de los tramos medio e inferior del río Paraná y el tramo inferior del río Uruguay desde ca. 2000 años AP hasta los momentos iniciales de la colonización europea (Caggiano 1984; Ceruti 1984; Ceruti y González 2007; Politis y Bonomo 2012; Rodríguez 1999). La construcción de montículos de tierra o cerritos; un intenso uso de la arcilla en las diferentes dimensiones de la cultura material; una economía mixta de caza, pesca, recolección con una horticultura a pequeña escala de la tríada maíz, poroto y zapallo; y un estilo cerámico distintivo (apéndices zoomorfos, siluetas recortadas sobre los bordes, "campanas" de alfarería, vasijas globulares cerradas, cucharas, entre otros) son los principales rasgos de esta entidad arqueológica (Ceruti 1984; González 1947; Politis y Bonomo 2012). Como lo han expresado varios autores (e.g. Bonomo et al. 2011a; Ceruti 2003; González 1977) Goya-Malabrigo sería la expresión arqueológica de los grupos indígenas del siglo XVI conocidos genéricamente como chaná-timbú.

En los últimos años ha existido un creciente interés por el estudio de Goya-Malabrigo, apoyado por nuevas perspectivas teóricas y mediante el uso de refinadas técnicas analíticas. En este sentido, las investigaciones que se vienen realizando de manera sistemática desde el año 2006 en el Delta Superior del río Paraná buscan ampliar el conocimiento sobre la arqueología del Nordeste argentino, entendida como historia indígena de larga duración y en particular sobre la entidad arqueológica Goya-Malabrigo (Bonomo et al. 2011 a y b; Politis et al. 2011). A partir de prospecciones intensivas realizadas en el Delta Superior y su llanura adyacente se relevaron un total de 84 sitios arqueológicos, de los cuales se excavaron sistemáticamente siete: Los Tres Cerros 1 y 2, Cerro Tapera Vázquez, Cerro Farall, Laguna del Negro 1 y Laguna de los Gansos 1 y 2.

En este artículo se presentan los resultados de los análisis arqueofaunísticos, cerámicos, bioarqueológicos y geoarqueológicos realizados en Laguna de los Gansos 1 y 2 (LDLG1 y LDLG2) y se dan a conocer los fechados radiocarbónicos obtenidos en ambos sitios. Esta información es contextualizada con aquella disponible para el área de estudio y discutida en relación con los modelos e hipótesis recientemente propuestos sobre la dispersión de la entidad arqueológica Goya-Malabrigo en el Paraná Medio e Inferior (Politis y Bonomo 2012, 2015). Como se verá más adelante, la cronología temprana de este sitio permite además abordar la génesis de Goya-Malabrigo a la luz de los nuevos modelos sobre etnogénesis (Voss 2015).

\section{Localidad arqueológica Laguna de los Gansos}

La localidad arqueológica Laguna de los Gansos (LDLG; Figura 1) se encuentra en el departamento Diamante (provincia de Entre Ríos) y está compuesta por tres sitios arqueológicos: LDLG1 (32²9'66,5" S y 60 38' 42,7" O), LDLG2 (32 $29^{\prime} 37,1^{\prime \prime}$ S y $60^{\circ} 38^{\prime} 25,7^{\prime \prime}$ O) y LDLG3 (32 $29^{\prime} 31,6^{\prime \prime} \mathrm{S}$ y $60^{\circ} 38^{\prime} 28,2^{\prime \prime} \mathrm{O}$ ). Los sitios están emplazados a lo largo de una extensa geoforma elevada (albardón) de $140 \mathrm{~m}$ de longitud, originada por la dinámica fluvial (Figura 2). Dicha dinámica incide en que durante las fases de aguas altas del río Paraná, el área sea afectada por inundaciones estacionales. Sobre este albardón se desarrollan especies arbóreas de timbó, típicas del bosque mixto fluvial, mientras que en la planicie adyacente se desarrollan pastizales altos y pajonales. Al Este se ubica la laguna homónima y al Oeste el riacho Timbó Colorado,

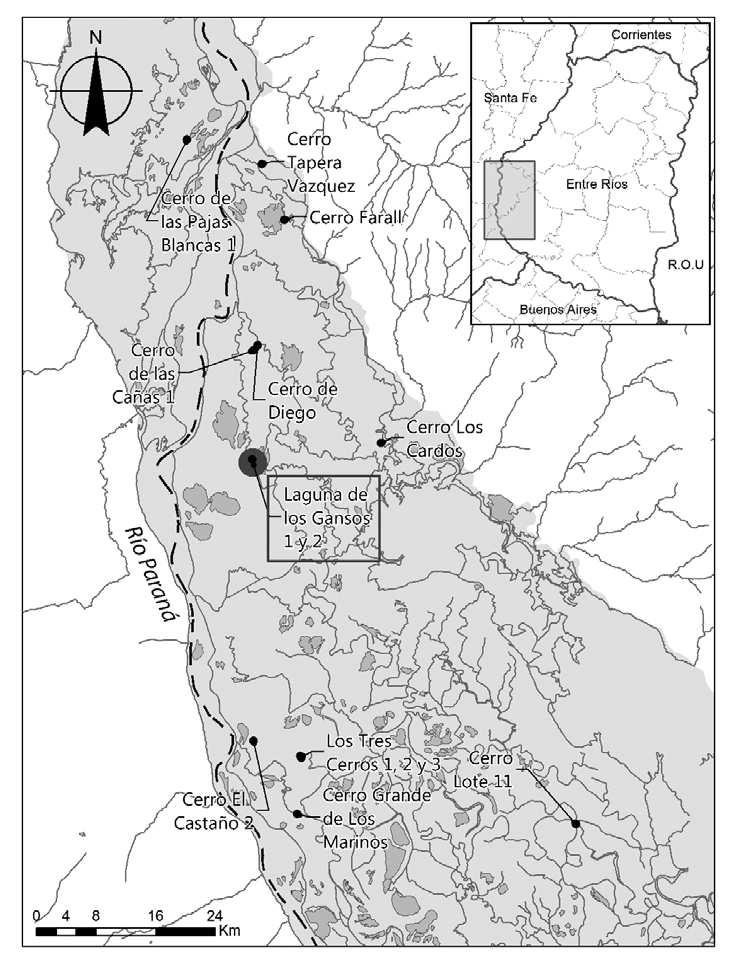

Figura 1. Localización de Laguna de los Gansos 1 y 2 y otros sitios arqueológicos mencionados en el texto.

Figure 1. Location of Laguna de los Gansos 1 and 2 and other archaeological sites mentioned in the text. 


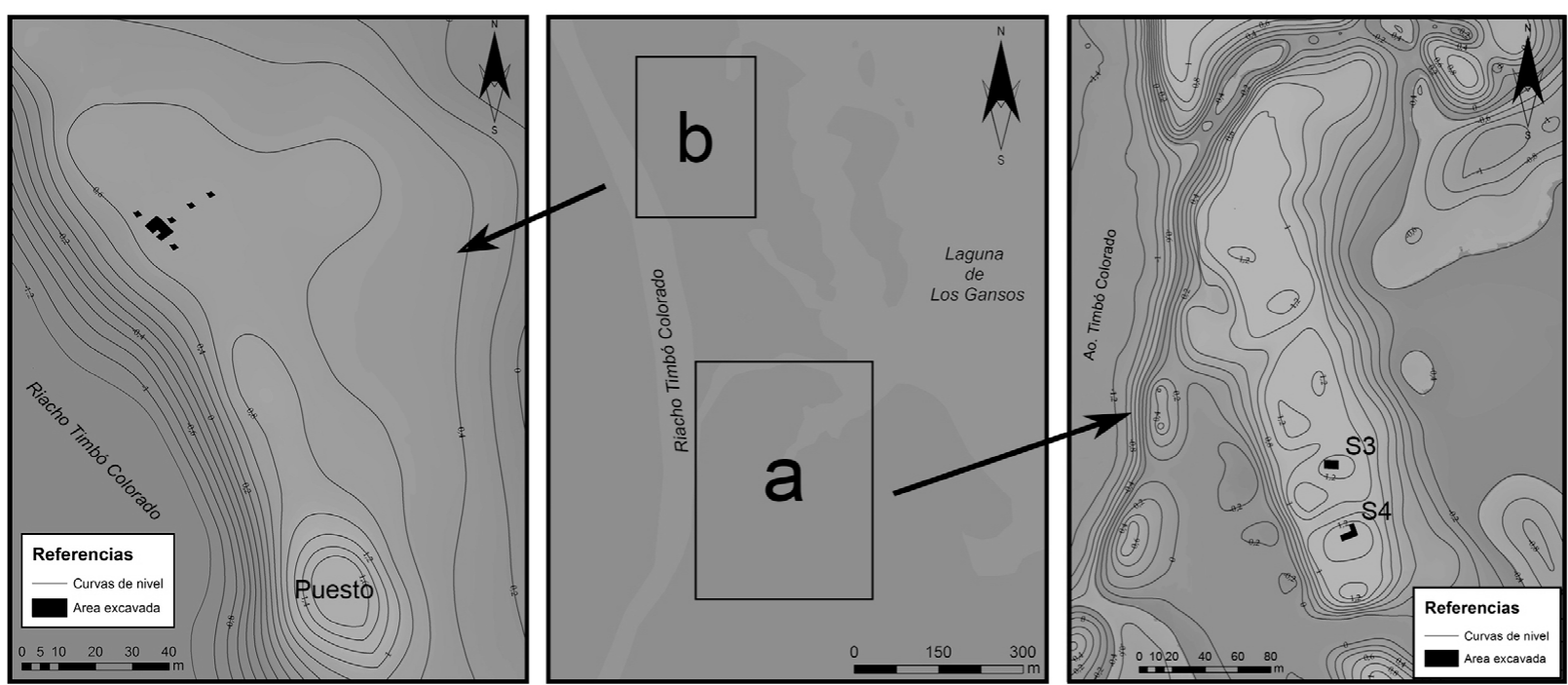

Figura 2. Laguna de los Gansos 1 y 2: detalle del área de estudio y geoformas asociadas; relevamiento topográfico con Estación Total de LGDLG1 (a) yLGDLG2 (b).

Figure 2. Laguna de los Gansos 1 and 2: detail of the study area and associated geoforms; Total Station topographic survey of LGDLG1 (a) and LGDLG2 (b).

en cuyas márgenes se encuentran praderas de herbáceas acuáticas latifolidas y graminiformes (véase Malvárez 1999).

El sitio LDLG1 fue detectado en el año 2007, después de una crecida extraordinaria del río Paraná que cubrió el albardón con más de un metro de agua. En ese momento se recuperó el material arqueológico mediante una recolección superficial sectorizada en cuatro unidades de muestreo a lo largo de un eje Norte-Sur: sectores 1, 2, 3 y 4 , siendo el sector 4 donde se observó la mayor densidad de materiales (Bonomo et al. 2010). Posteriormente, entre 2012 y 2014 se llevaron a cabo tres campañas durante las cuales se excavaron LDLG1 y LDLG2. Como se puede observar en la Tabla 1, se obtuvieron cinco fechados radiocarbónicos por AMS que ubican a LDLG1 entre 1775 y 1236 años ${ }^{14} \mathrm{C}$ AP y a LDLG2 entre 570 y 590 años ${ }^{14} \mathrm{C}$ AP.

\section{Metodología de los análisis cerámico,} arqueofaunístico y bioarqueológico

El análisis de los conjuntos cerámicos de LDLG1 y LDLG2 incluyó variables tecno-morfológicas (e.g. tratamiento de superficie, tipo de borde, atmósfera de cocción), estilísticas (técnicas y motivos decorativos) (Primera Convención Nacional de Antropología 1966; Rice 1987; Rye 1981) y tafonómicas (i.e. marcas de uso y alteraciones postdepositacionales) (Sanhueza Riquelme 1998; Schiffer y Skibo 1989) a partir de las cuales se evaluaron posibles elecciones técnicas y funcionales. Además, se remontaron fragmentos para reconstruir las formas y tipos cerámicos (Balfet et al. 1992; Orton et al. 1997; Rice 1987).

Los estudios arqueofaunísticos en LDLG1 y LDLG2 estuvieron dirigidos, en primer lugar, a conocer la diversidad taxonómica representada en los sitios. En el caso de LDLG1, donde los análisis fueron más detallados, se buscó identificar los procesos tafonómicos que intervinieron en la formación del conjunto y comenzar a discutir las prácticas de procesamiento a partir de las cuales los recursos faunísticos fueron transformados en alimentos $u$ otros productos (e.g. cueros, instrumentos óseos). Con estos objetivos, se realizó la identificación a nivel de elemento anatómico, porción, lateralidad y al mayor nivel taxonómico posible. La cuantificación de la abundancia anatómica y taxonómica de LDLG1 se llevó

\begin{tabular}{|c|c|c|c|c|}
\hline Sitio arqueológico & $\begin{array}{l}\text { Código de la } \\
\text { muestra }\end{array}$ & Edad años $C^{14} A P$ & Material datado & \multirow{3}{*}{$\begin{array}{l}\text { Tabla 1. Fechados } \\
\text { - radiocarbónicos } \\
\text { obtenidos en } \\
\text { la localidad } \\
\text { arqueológica } \\
\text { Laguna de los } \\
\text { Gansos. }\end{array}$} \\
\hline $\begin{array}{l}\text { Laguna de los Gansos } 2 \\
\text { (individuo 1) }\end{array}$ & AA-98851 & $570 \pm 43$ & Cuboide de Homo sapiens & \\
\hline $\begin{array}{l}\text { Laguna de los Gansos } 2 \\
\text { (individuo 2) }\end{array}$ & AA-103899 & $590 \pm 46$ & Costilla de Homo sapiens & \\
\hline $\begin{array}{l}\text { Laguna de los Gansos } 1 \\
\quad \text { (Sector 3, Nivel 3) }\end{array}$ & AA-98847 & $1236 \pm 46$ & $\begin{array}{l}\text { Hueso largo de fauna con fractura } \\
\text { helicoidal }\end{array}$ & \multirow{3}{*}{$\begin{array}{l}\text { Table } 1 . \\
\text { Radiocarbon } \\
\text { dates obtained } \\
\text { for Laguna } \\
\text { de los Gansos } \\
\text { archaeological } \\
\text { locality. }\end{array}$} \\
\hline $\begin{array}{l}\text { Laguna de los Gansos } 1 \\
\text { (Sector 4, Nivel 4) }\end{array}$ & AA-98845 & $1740 \pm 47$ & $\begin{array}{c}\text { Hueso largo de fauna con fractura } \\
\text { helicoidal }\end{array}$ & \\
\hline $\begin{array}{l}\text { Laguna de los Gansos } 1 \\
\text { (Sector 4, Nivel 2) }\end{array}$ & AA-103901 & $1775 \pm 51$ & Tibia de Myocastor coypus & \\
\hline
\end{tabular}


a cabo a través de diferentes medidas de abundancia (NISP, NMI, MNE, MAU y MAU\%) (Lyman 2008; Mengoni Goñalons 1999, 2010). A los fines de evaluar si los perfiles anatómicos se encuentran mediatizados por la DMO, se correlacionó el porcentaje de supervivencia de sitios de escaneo de Myocastor coypus y Blastocerus dichotomus con los valores de DMO disponibles para lepóridos (Pavao y Stahl 1999) y Rangifer tarandus (Lam et al. 1999), respectivamente ${ }^{1}$. Además, se relevó la meteorización (Andrews 1990; Behrensmeyer 1978), la presencia de distintas marcas de origen natural (roedores, carnívoros y raíces), la depositación química y los estadios de abrasión y pulimento ligados a la abrasión sedimentaria in situ o al transporte fluvial (Fisher 1995; Gutiérrez 2004; Gutiérrez y Kauffman 2007; Lyman 1994).

Por otra parte, en LDLG1 se analizaron las marcas de origen antrópico de acuerdo a su ubicación en la topografía ósea, frecuencia y morfología (profundidad, orientación y largo) a los fines de indagar sobre las etapas de procesamiento de las distintas especies representadas en el sitio (Escosteguy et al. 2012; Lloveras et al. 2009; Mengoni Goñalons 1999). En los casos que pudieron determinarse (véase más abajo), se registró la termoalteración para discutir actividades vinculadas con el manejo del fuego. Por último, se analizaron los patrones de fractura y se calculó la intensidad de fragmentación de los huesos largos a partir del índice de fragmentación (NISP/MNE) (Lyman 1994).

1 Al no contar con valores densitométricos para las especies representadas en el sitio, se utilizan como proxies los valores calculados para lepóridos (Pavao y Stahl 1999) y Rangifer tarandus (Lam et al. 1999). Se optó por utilizar estos datos de densidad ya que se basan en cálculos que tienen en cuenta el ajuste de forma. Si bien existen datos densitométricos para especies con mayor cercanía taxonómica y/o similitud morfológica -Marmota spp. (Lyman et al. 1992) y Odocoileuss spp. (Lyman 1984)- se priorizó la precisión de los

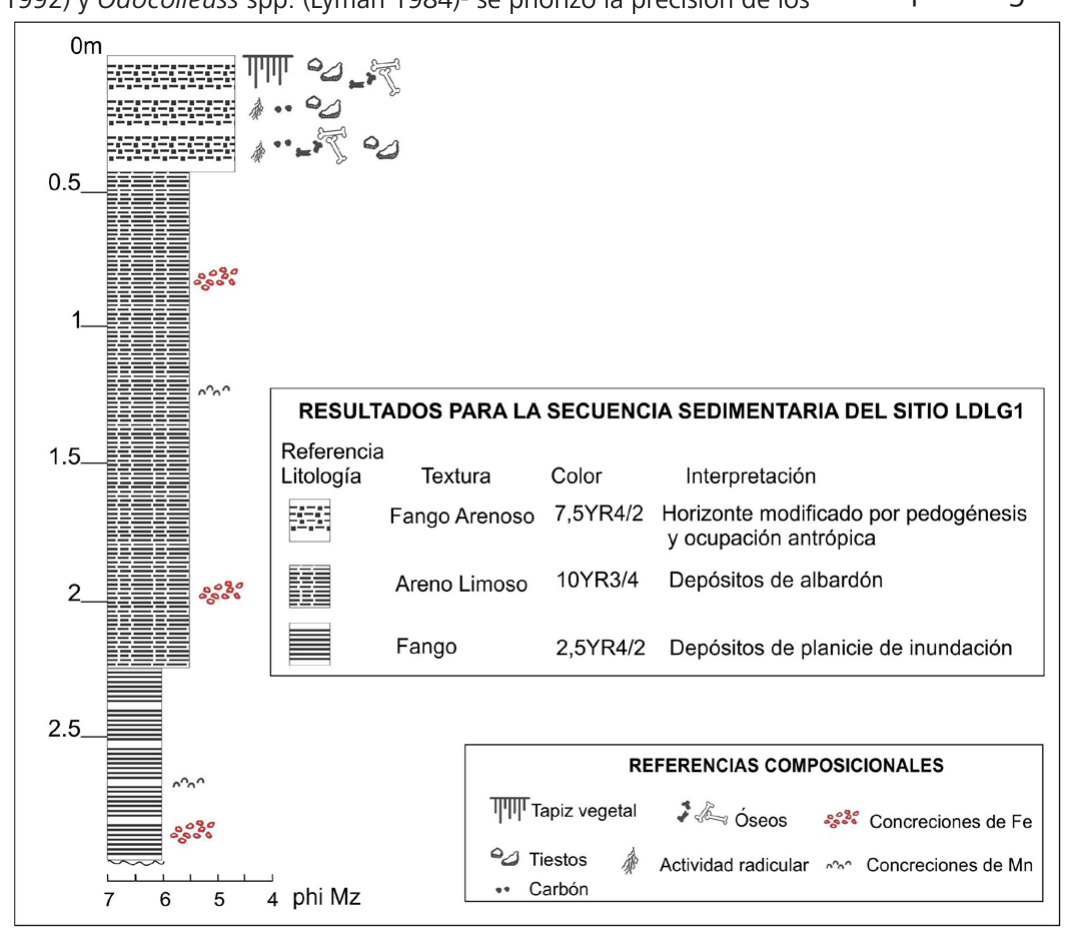

El análisis bioarqueológico llevado a cabo sobre el conjunto osteológico hallado en LDLG2 estuvo orientado a determinar el sexo y la edad de los individuos, relevar señales paleopatológicas de distintas etiologías y caracterizar las prácticas mortuorias. Las determinaciones sexo-etarias se realizaron siguiendo los criterios bioarqueológicos estándar (Buikstra y Ubelaker 1994; Ubelaker 1999; White y Folkens 2005). El sexo se determinó a partir de la observación de ciertos rasgos en los coxales: la escotadura ciática mayor, el arco ventral, el ángulo subpúbico y las características de la rama isquiopúbica. La edad de los individuos adultos se calculó a partir de las características de la sínfisis púbica siguiendo el método de Todd (1920 en Buikstra y Ubelaker 1994) y de la carilla auricular del ilion según Lovejoy y colaboradores (1985 en Buikstra y Ubelaker 1994). Por otro lado, se comenzó el relevamiento de patologías, tanto sobre el esqueleto craneal como el postcraneal. Se relevaron señales de estrés metabólico-nutricional, de infecciones, de traumatismos y de patologías degenerativas a nivel de las articulaciones (Waldron 2009). Esto permitirá tener una primera aproximación al estado de salud de los individuos. Finalmente, para cada esqueleto se consignó la modalidad de inhumación, orientación de los esqueletos y acompañamiento mortuorio y se relevó la presencia de huellas de corte (Buikstra y Ubelaker 1994).

\section{Sitio arqueológico Laguna de los Gansos 1}

En este sitio se excavaron $44 \mathrm{~m}^{2}$ en los sectores $3\left(8 \mathrm{~m}^{2}\right)$ y $4\left(36 \mathrm{~m}^{2}\right)$. Las sucesiones sedimentarias expuestas en los perfiles de la excavación y las reconocidas mediante perforaciones con barreno fueron muestreadas cada 5 $\mathrm{cm}$ y diferenciadas por sus características colorimétricas, texturales y composicionales (Figura 3). Los materiales arqueológicos se recuperaron inmediatamente por debajo del tapiz vegetal actual, entre los 5 a $35 \mathrm{~cm}$ de profundidad. Las evidencias arqueológicas se concentran en el horizonte húmico fango arenoso (esmectíticos, illíticos-cloríticos-caoliníticos) que se desarrolla por encima de los depósitos areno fangosos a arenosos del albardón.

\section{Análisis de la alfarería}

La muestra de alfarería analizada hasta el momento se compone de 4711 fragmentos recuperados en los sectores 3 y 4 . Dominan los tiestos, de los cuales el 82,3\% ( $n=$ 3880) son fragmentos de cuerpos/bases de vasijas y el $16,5 \%(n=780)$ corresponde a bordes. El resto $(n=51 ; 1,1 \%)$ está

Figura 3. Secuencia arqueoestratigráfica para el sitio LDG1.

Figure 3. Archaeostratigraphic sequence of LDG1 site. 
compuesto por masas de arcilla cruda y cocida, apéndices, asas y fragmentos indeterminados. La mayoría de los tiestos presenta tratamiento alisado de sus superficies internas $(n=3574)$ y externas $(n=3106)$ y, en segundo lugar, encontramos superficies pulidas, tanto internas $(n=$ 569) como externas $(n=747)$. Algunos fragmentos $(n=$ 222) también poseen un pulido aparentemente generado por flujo plástico, producto de algún agente abrasivo como el sustrato o partículas suspendidas en agua (Schiffer y Skibo 1989; Winter et al. 2010). A partir de variaciones cromáticas en fracturas frescas (García Roselló y Calvo Trías 2006; Rye 1981), se infiere que las piezas fueron cocidas principalmente en atmósferas de cocción oxidante, completa (10\%; $n=258)$ e incompleta $(71,2 \%$; $n=3337)$. Algunos fragmentos $(17,9 \% ; n=841)$ muestran secuencias cromáticas en tonos de grises y negros, lo cual puede deberse a una oxidación con material orgánico sin consumir o a una atmósfera reductora.

La mayoría del material presenta marcas por uso o alteraciones posteriores a su descarte y que muchas veces ocultan las primeras. El $70,7 \%(n=3313)$ de las superficies internas se encuentran abradidas y el $39,5 \%$ $(n=1853)$ tiene algún grado de agrietamiento; ocurre lo mismo en las superficies externas en porcentajes similares (68,9\%; $n=3229$ y 37,4\%; $n=1752$, respectivamente). Otras alteraciones observadas son el redondeamiento de planta y sección $(70,7 \% ; n=3314)$, el efecto pedestal $(n=204)$ provocado por la remoción de la matriz arcillosa (Sanhueza Riquelme 1998; Schiffer y Skibo 1989), la delaminación $(n=608)$, pequeños desprendimientos de superficie $(n=175)$ y marcas de pequeñas raíces $(n=43)$. Sólo 17 tiestos muestran restos de hollín, dos de ellos -con una gruesa capa adherida en la superficie internafueron remontados.

La decoración es relativamente escasa, está presente en el $11,5 \%(n=541)$ del conjunto. Las técnicas identificadas son la aplicación de pigmento, incisión (en sus distintas variantes de punto, de línea y de surco rítmico), modelado y modelado/pastillaje. Estas técnicas se presentan aisladas o en varias combinaciones. El agregado de colorante rojo ( $n=339)$ se observó, en la mayoría de los casos, en las superficies internas, mientras que los motivos modelados $(n=19)$ e incisos $(n=196)$ se observan generalmente en las superficies externas y en los labios. Los motivos incisos incluyen líneas rectas paralelas y en zig-zag, triángulos y punteado; las improntas generalmente son de forma triangular, encontrándose menos representadas las huellas circulares y rectangulares.

Una combinación particular de modelado o pastillaje con incisión se observó en 11 fragmentos que presentan en su superficie externa prominencias alargadas, de lomo redondeado y forma sinuosa o en arcos que fueron complementadas con punteado y bordeadas con incisiones de línea. Estos elementos se corresponderían con lo que Schmitz y colaboradores denominaron

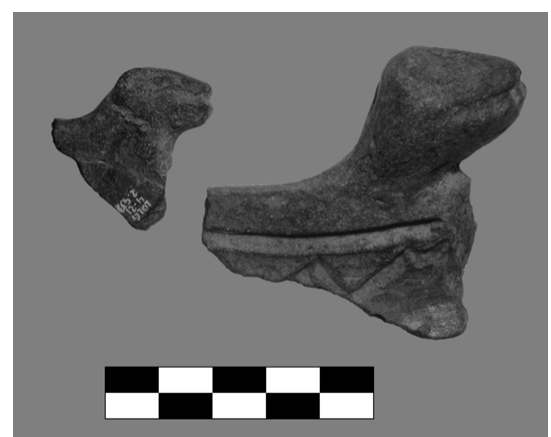

Figura 4. Modelados cerámicos zoomorfos hallados en LDLG1.

Figure 4. Zoomorphic appendages recovered at LDLG1.

"crestas" (1972: 26) y que definen la "Unidad Decorativa $X^{\prime \prime}$ presente en los tipos cerámicos "Goya inciso fino" y "Goya inciso grueso" del sitio Paraná Miní 1. A su vez, Ceruti (2003) menciona su abundancia en otros sitios como Arroyo Las Mulas 1 y los interpreta como posibles representaciones de ofidios. En un fragmento de LDLG1 también se observó la aplicación de pastillaje pero en forma de círculo con incisiones de punto en el interior y exterior de la circunferencia. Por otro lado, en 10 fragmentos se identificó el diseño de "banderitas" (González y Frère 2010), que corresponden al menos a dos piezas distintas. Finalmente, dentro de los modelados se hallan dos zoomorfos pequeños, una cabeza de mamífero y una probable cabeza de reptil (Figura 4).

Es interesante mencionar que se observaron fragmentos con núcleos aún crudos y con irregularidades en los bordes y los acabados. En estos casos la mayoría de las incisiones presentan improntas y trazos irregulares que posiblemente estén relacionados con la textura poco alisada de la superficie y con la consistencia demasiado fresca de la pasta, evidenciada por las rebabas.

Como resultado de las tareas de remontaje se asociaron 395 tiestos. Sin embargo, si consideramos las uniones de fracturas recientes como un único fragmento, el número real disminuye a 268. Las distancias vertical y horizontal entre fragmentos asociados son muy variables, ya que oscilan entre 0-17 y 0-360 cm, respectivamente (con un promedio de 3,5 y 59,7 cm). La mayoría de los remontajes, 75 en total, comprenden uniones de dos $(n=40)$ o tres $(n=17)$ fragmentos. La reconstrucción más completa corresponde a 27 fragmentos de un pequeño cuenco de forma globular de $7 \mathrm{~cm}$ de altura y $10 \mathrm{~cm}$ de diámetro de boca. En otros casos se pudieron reconstruir los perfiles de las formas y determinar con mayor exactitud las partes de la vasija representadas y los diámetros de boca. Las formas que se han podido identificar incluyen 4 platos, 2 fuentes y 4 cuencos medianos a pequeños (de acuerdo a Balfet et al. 1992). Algunos bordes cerrados y de paredes rectas pueden corresponder a cuellos o jarros. Otros, de paredes más gruesas y divergentes, podrían formar parte de cerámicas tubulares (Ghiani Echenique et al. 2013; Vignati 1942) o bien de las denominadas campanas (Gaspary 1950). Por último, se calcularon los diámetros a partir de fragmentos de bordes, para lo cual se consideraron aquellos que superaran el $5 \%$ del perímetro total $(n=325)$ a fin de brindar mayor confiabilidad al valor estimado. 
Los bordes se atribuyeron a recipientes pequeños: 5-13 $\mathrm{cm}(\mathrm{n}=174)$, medianos: $14-28 \mathrm{~cm}(\mathrm{n}=133)$ y grandes: $29-40 \mathrm{~cm}(n=18)$.

Por último, siete tiestos de los sectores 3 y 4 fueron analizados en búsqueda de almidones y fitolitos (Colobig et al. 2014). Los resultados muestran la existencia de restos herbáceos y almidones que podrían incluir Zea mays, pero la evidencia no es aun conclusiva.

\section{Análisis de los restos arqueofaunísticos}

La muestra analizada en LDLG1 comprende un total de 1294 restos arqueofaunísticos procedentes de las cuadrículas 7 a 10 del sector 4 . En estas cuadrículas se recuperaron además 1550 fragmentos indeterminados menores a $2 \mathrm{~cm}$ que no se incluyeron en el análisis. El conjunto arqueofaunístico de LDLG1 se caracteriza, en primer lugar, por la elevada frecuencia de Myocastor coypus, tanto en términos de NISP como de NMI (Tabla 2). Para este roedor, se identificó un NMI de 12 a partir de hemimandíbula y fémur, que son los elementos más abundantes. En cuanto al perfil anatómico se observa que, en términos generales, el esqueleto apendicular está mejor representado que el axial y, a su vez, los elementos del miembro posterior presentan valores de MAU\% más elevados que el miembro anterior (Tabla 3, Figura 5). Como se observa en la Tabla 2, Hydrochoerus hydrochaeris y, en menor medida, Blastocerus dichotomus

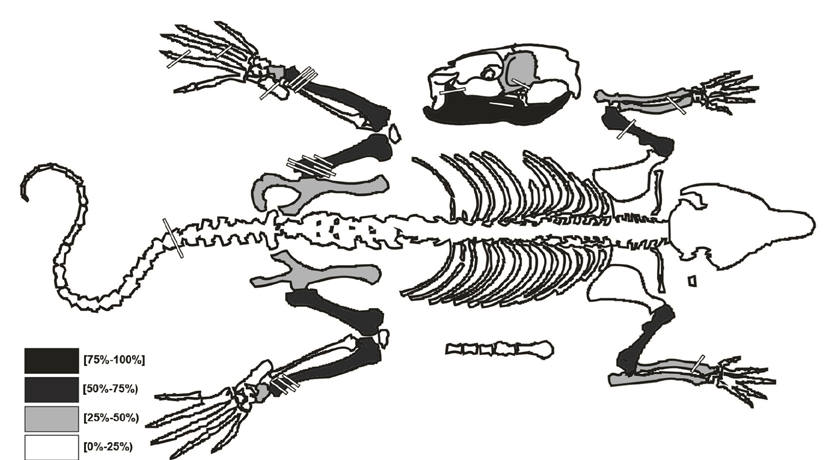

Figura 5. Valores de MAU\% para Myocastor coypus. Las líneas representan la ubicación de las huellas de corte

Figure 5. \%MAU values for Myocastor coypus. The lines represent the location of cut marks.

se encuentran entre los taxones más abundantes en el conjunto. Para la primera especie se calculó un NMI de 4 a partir de ulnas y para Blastocerus dichotomus un $\mathrm{NMI}$ de 2 a partir de premolares y radios. Cabe destacar que en ambas especies el esqueleto apendicular está sobrerepresentado en relación al axial, al igual que en el caso del coipo (Tabla 3). Entre las especies minoritarias en el conjunto, se identificaron escasos restos de cávidos y sigmodontinos así como un pequeño conjunto, pero altamente diverso, de carnívoros: cánidos, dos especies de mustélidos (Lontra longicaudis y Galictis cuja), un félido pequeño (c.f. Oncifelis geoffroyi) y uno grande (una patela que podría corresponder a Panthera onca o Puma

\begin{tabular}{llllll}
\hline Taxón & NMI & NISP & NISP hc & NISP ter & NISP frac \\
\hline Myocastor coypus & 12 & 458 & 20 & 10 & 0 \\
Hydrochoerus hydrochaeris & 4 & 141 & 9 & 7 & 3 \\
Cavia aperea & 1 & 2 & 0 & 0 & 0 \\
Sigmodontinae & - & 3 & 0 & 0 & 0 \\
Rodentia & - & 10 & 0 & 0 & 0 \\
Blastocerus dichotomus & 2 & 58 & 3 & 10 & 5 \\
Artiodactyla & - & 10 & 0 & 3 & 7 \\
Lontra longicaudis & 1 & 2 & 1 & 0 & 0 \\
Galictis cuja & 1 & 1 & 0 & 0 & 0 \\
Felidae & - & 3 & 1 & 0 & 0 \\
Felidae c.f. Oncifelis geoffroyi & 1 & 1 & 0 & 0 & 0 \\
Canidae & - & 5 & 2 & 0 & 0 \\
Carnivora & - & 1 & 0 & 0 & 0 \\
Mammalia & - & 204 & 9 & 8 & 6 \\
Mammalia (tamaño pequeño) & - & 95 & 4 & 1 & 0 \\
Mammalia (tamaño grande) & - & 194 & 3 & 20 & 21 \\
Siluriformes & - & 12 & 0 & 1 & 0 \\
Actinopterygii & - & 44 & 0 & 4 & 0 \\
Aves & - & 1 & 0 & 0 & 0 \\
Amphibia & - & 1 & 0 & 1 & 0 \\
Indeterminados & - & 48 & 0 & 0 & 0 \\
\hline Total & - & 1294 & 52 & 67 & 42 \\
\hline & & & & & \\
\hline
\end{tabular}

Tabla 2. Valores de NISP y NMI calculados para LDLG1. NISP hc: NISP con huellas de corte; NISP ter: NISP con termoalteración; NISP fract: NISP con fracturas antrópicas.

Table 2. NISP and MNI values for the LDLG1 assemblage. NISP hc: NISP with cut marks; NISP ter: NISP with thermal alteration; NISP fract: NISP with anthropic fractures. 


\begin{tabular}{|c|c|c|c|c|c|c|c|c|c|c|c|c|}
\hline \multirow[t]{2}{*}{ Elemento } & \multicolumn{4}{|c|}{ Myocastor coypus } & \multicolumn{4}{|c|}{ Hydrochoerus hydrochaeris } & \multicolumn{4}{|c|}{ Blastocerus dichotomus } \\
\hline & NISP & MNE & MAU & MAU\% & NISP & MNE & MAU & MAU\% & NISP & MNE & MAU & MAU\% \\
\hline Cráneo & 13 & 2 & 2 & 16,66 & 10 & 2 & 2 & 66,66 & 2 & 1 & 1 & 66,66 \\
\hline Maxilar & 13 & 8 & 4 & 33,33 & 7 & 1 & 0,5 & 16,66 & 0 & 0 & 0 & 0 \\
\hline Incisivos & 51 & 24 & - & - & 0 & 0 & - & - & 0 & 0 & - & - \\
\hline $\begin{array}{l}\text { Molares y } \\
\text { premolares }\end{array}$ & 43 & 42 & - & - & 6 & 2 & - & - & 4 & 4 & - & - \\
\hline Hemimandíbula & 38 & 24 & 12 & 100 & 8 & 3 & 1,5 & 50 & 2 & 1 & 0,5 & 33,33 \\
\hline V. cervical & 5 & 4 & 0,57 & 4,75 & 5 & 2 & 0,28 & 9,5 & 0 & 0 & 0 & 0 \\
\hline V. torácica & 6 & 5 & 0,41 & 3,41 & 3 & 3 & 0,23 & 7,66 & 5 & 2 & 0,15 & 10,2 \\
\hline V. lumbar & 6 & 4 & 0,57 & 4,75 & 1 & 1 & 0,16 & 5,53 & 0 & 0 & 0 & 0 \\
\hline V. sacra & 1 & 1 & 0,25 & 2,08 & 0 & 0 & 0 & 0 & 0 & 0 & 0 & 0 \\
\hline V. caudal & 59 & 54 & 2 & 16,66 & 1 & 1 & 0,16 & 5,33 & 0 & 0 & 0 & 0 \\
\hline V. indet & 0 & 0 & - & - & 2 & 2 & - & - & 0 & 0 & - & - \\
\hline Costilla & 2 & 2 & 0,08 & 0,66 & 3 & 2 & 0,07 & 2,53 & 0 & 0 & 0 & 0 \\
\hline Escápula & 4 & 4 & 2 & 16,66 & 2 & 1 & 0,5 & 16,66 & 0 & 0 & 0 & 0 \\
\hline Húmero & 15 & 12 & 6 & 50 & 3 & 1 & 0,5 & 16,66 & 5 & 2 & 1 & 66,66 \\
\hline Radio & 15 & 8 & 4 & 33,33 & 5 & 3 & 1,5 & 50 & 3 & 3 & 1,5 & 100 \\
\hline Ulna & 10 & 10 & 5 & 41,66 & 7 & 6 & 3 & 100 & 0 & 0 & 0 & 0 \\
\hline Carpianos & 1 & 1 & 0,07 & 0,58 & 4 & 4 & 0,25 & 8,33 & 1 & 1 & 0,08 & 5,33 \\
\hline Hemipelvis & 12 & 8 & 4 & 33,33 & 1 & 1 & 0,5 & 16,66 & 1 & 1 & 0,5 & 33,33 \\
\hline Fémur & 25 & 17 & 8,5 & 70,83 & 3 & 3 & 1,5 & 50 & 3 & 1 & 0,5 & 33,33 \\
\hline Tibia & 24 & 13 & 6,5 & 54,16 & 6 & 3 & 1,5 & 50 & 2 & 1 & 0,5 & 33,33 \\
\hline Rótula & 2 & 2 & 1 & 8,33 & 3 & 3 & 1,5 & 50 & 2 & 2 & 1 & 66,66 \\
\hline Calcáneo & 4 & 4 & 2 & 16,66 & 3 & 2 & 1 & 33,33 & 2 & 1 & 0,5 & 33,33 \\
\hline Astrágalo & 6 & 6 & 3 & 25 & 4 & 4 & 2 & 66,66 & 1 & 1 & 0,5 & 33,33 \\
\hline Tarsianos & 5 & 5 & 0,5 & 4,16 & 4 & 4 & 0,4 & 13,33 & 3 & 3 & 0,5 & 33,33 \\
\hline Metapodio & 6 & 5 & - & - & 5 & 5 & - & - & 1 & 1 & - & - \\
\hline Metatarso & 25 & 19 & 1,9 & 15,83 & 7 & 7 & 0,87 & 29,16 & 4 & 1 & 0,5 & 33,33 \\
\hline Metacarpo & 5 & 5 & 0,5 & 4,16 & 6 & 6 & 0,75 & 25 & 1 & 1 & 0,5 & 33,33 \\
\hline Falanges & 62 & 58 & 1,07 & 8,91 & 32 & 11 & 0,26 & 8,7 & 16 & 12 & 0,5 & 33,33 \\
\hline Total & 458 & 347 & - & - & 141 & 83 & - & - & 58 & 39 & - & - \\
\hline
\end{tabular}

Tabla 3. Abundancia anatómica para los taxones mejor representados de LDLG1

Table 3. Skeletal representation for the most frequent taxa in the LDLG1 assemblage.

concolor). En comparación con los mamíferos, los restos óseos de peces son poco abundantes y corresponden fundamentalmente a espinas de Siluriformes y vértebras indeterminadas. Finalmente, pudieron identificarse tan solo 2 restos asignados a aves y anfibios.

En relación con la representación diferencial de partes anatómicas de Myocastor coypus, se observa una correlación relativamente débil pero positiva y estadísticamente significativa $\left(r_{s}=0,473, p=0,001\right)$ entre los porcentajes de supervivencia de las distintas partes esqueletarias y los valores de DMO. Esto permite afirmar que los procesos de destrucción mediados por la densidad han modelado el perfil esqueletario de este taxón (Figura 6). En el caso de Blastocerus dichotomus, la correlación entre estas variables no arrojó un valor estadísticamente significativo $\left(r_{s}=0,145, p=0,156\right)$. Sin embargo, esto podría deberse al pequeño tamaño de la muestra de cérvidos analizada hasta el momento.

En cuanto al perfil de meteorización, se observó una escasa proporción de huesos meteorizados $(20,3 \%)$, la mayoría correspondiente a los estadios iniciales, por lo que se infiere un enterramiento relativamente rápido del conjunto. En algunos casos (32,7\%), se identificaron huesos con superficies brillosas y textura suave (estadio $1=5,4 \%$ ) y/o con bordes redondeados (estadio 2-3= $27,3 \%)$. Estas modificaciones se asocian con la abrasión sedimentaria y alertan sobre la necesidad de tener en cuenta el rol del agua en la formación del conjunto.

La mayoría de los huesos presenta una coloración oscura $(78,5 \%)$, lo cual puede asociarse en muchos casos a la depositación química en contacto con la matriz sedimentaria. En aquellos especímenes donde la coloración no fue total, se pudo identificar la depositación de óxido de manganeso. Esta tinción de los huesos imposibilitó reconocer la termoalteración, a excepción de los huesos calcinados que presentan una coloración blanco-azulada. En cuanto a las marcas sobre las superficies óseas, se registró una elevada proporción de marcas de raíces $(51,9 \%)$. También se identificaron marcas de roedores $(3,6 \%)$ y de carnívoros $(0,5 \%)$ en bajos porcentajes. 

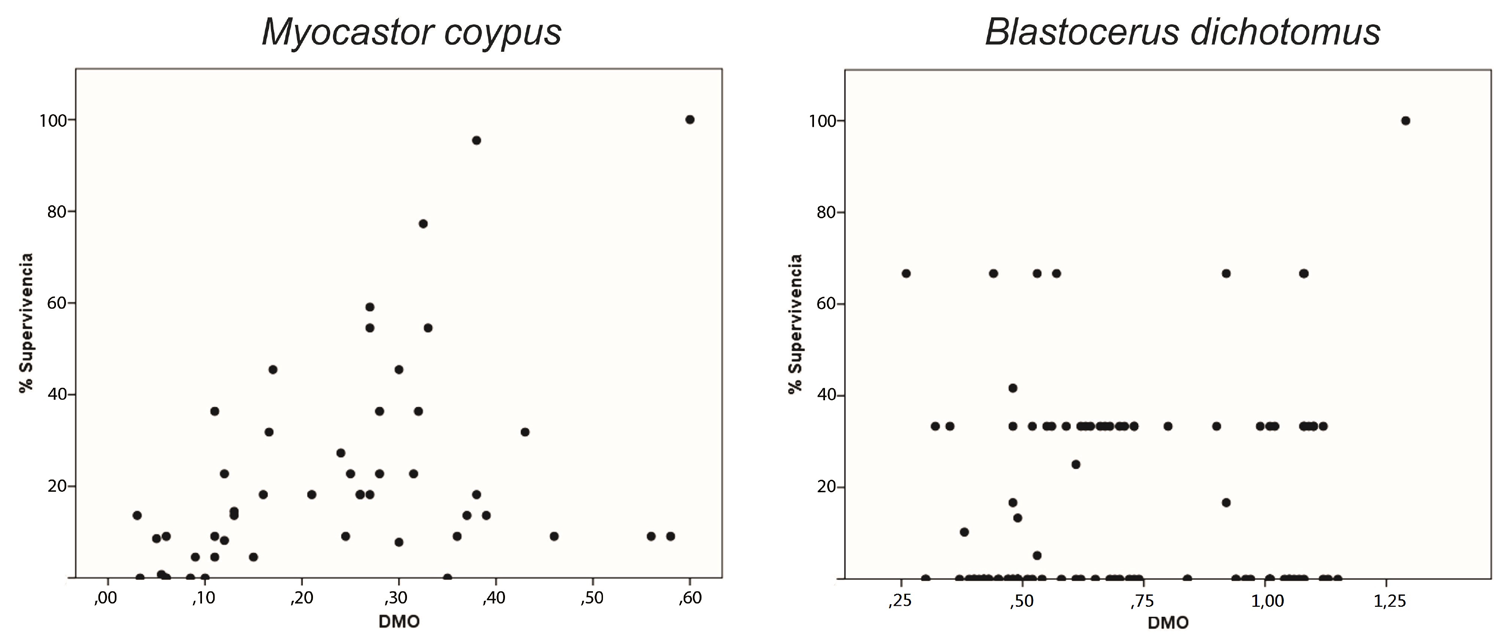

Figura 6. Relación entre DMO y porcentaje de supervivencia de sitios de escaneo de Myocastor coypus y Blastocerus dichotomus.

Figure 6. Relation between BMD and percentage survivorship of scan sites of Myocastor coypus and Blastocerus dichotomus.

En cuanto a las evidencias de procesamiento de los recursos faunísticos, se registraron huellas de corte, termoalteración y fracturas frescas sobre varios de los taxones identificados en el sitio (Tabla 2). En el caso de Myocastor coypus, se registraron huellas de corte sobre 21 elementos (Figura 5), que pueden ser atribuidas según su ubicación y morfología a diferentes actividades (cuereo, desarticulación y descarne) en base a los modelos desarrollados en estudios experimentales y etnoarqueológicos (Escosteguy y Vigna 2010; Escosteguy et al. 2012; Lloveras et al. 2009). El cuereo puede reconocerse a partir de huellas ubicadas en la diáfisis distal de tibia $(n=6)$, metapodio y falanges $(n=2)$. En el esqueleto axial, este tipo de huellas se ubican paralelas a los molariformes de la hemimandíbula $(n=1)$, en la apófisis cigomática del maxilar $(n=1)$ y en vértebras caudales $(n=1)$. Las huellas ubicadas en el proceso condilar de la hemimandíbula $(n=1)$ se produjeron probablemente al desarticular este elemento del cráneo, mientras que aquellas ubicadas en el sector proximal de la diáfisis de fémures $(n=5)$ y distal de radios $(n=2)$ podrían vincularse en algunos casos a actividades de desarticulación o bien al descarne. Por último, las huellas sobre el húmero $(n=1)$ probablemente representen actividades de descarne y las ubicadas sobre el calcáneo $(n=1)$ podrían corresponder al cuereo o a la desarticulación. En cuanto a las evidencias de termoalteración sobre este roedor, se registraron falanges y vértebras caudales calcinadas $(n=6)$.

En el caso de Hydrochoerus hydrochaeris, se registraron huellas de corte en el sector anterior de la hemimandíbula y paralelas a molariformes $(n=2)$ que podrían vincularse al cuereo mientras que las huellas sobre el proceso cigomático del maxilar $(n=1)$ podrían atribuirse a esa actividad o, alternativamente, al aprovechamiento de los importantes músculos masticatorios de este roedor. Las huellas ubicadas sobre la cabeza del fémur $(n=1)$, extremo proximal de cúbito y radio $(n=2)$ y epífisis proximal de metacarpiano $(n=1)$ podrían deberse a la desarticulación a nivel del miembro posterior, codo y manos, mientras que las ubicadas sobre la hoja escapular y diáfisis de tibia $(n=2)$ se asociarían al descarne. En cuanto a Blastocerus dichotomus, se registraron huellas de corte sobre diáfisis de húmero y radio $(n=2)$, atribuibles al descarne, y sobre un navicular, posiblemente relacionada a actividades de desarticulación. La termoalteración sobre este taxón se presenta sobre falanges, tarso y metatarso. Por último, se observaron huellas de corte sobre varios carnívoros: en patela de félido grande, sobre diáfisis de húmero de Lontra longicaudis y sobre calcáneo y vértebra de cánido.

Por otra parte, se registraron fracturas frescas en cúbitos y tibia $(n=3)$ de Hydrochoerus hydrochaeris, asociadas en dos casos a aserrado perimetral. Asimismo, se identificaron fracturas frescas en metapodios, húmero y radio $(n=5)$ de Blastocerus dichotomus así como sobre metapodios asignados a la categoría Artiodactyla $(n=7)$, que muy probablemente correspondan a este cérvido. También cabe destacar que se hallaron varios huesos largos de mamíferos grandes indeterminados con fracturas frescas helicoidales y longitudinales $(n=$ 21). En cuanto a los índices de fragmentación (NISP/ MNE) de los huesos largos, se halló que los valores correspondientes a Blastocerus dichotomus y Artiodactyla (tomados en conjunto) ${ }^{2}$ se alejan de forma significativa de los calculados tanto para Myocastor coypus como para Hydrochoerus hydrochaeris que, a su vez, presentan entre sí valores semejantes de fragmentación (ANOVA: $\mathrm{F}=5,26 ; \mathrm{N}=23 ; \mathrm{p}=0,015 /$ Tukey post-hoc test: $\mathrm{P}<0,05)$.

\section{Sitio arqueológico Laguna de los Gansos 2}

El sitio LDLG2 se encuentra localizado en la entrada de un corral adyacente a un puesto rural. La información sobre este sitio fue brindada por los pobladores del

\footnotetext{
${ }^{2}$ El índice de fragmentación de artiodáctilos fue calculado considerando en conjunto los huesos largos asignados a Blastocerus dichotomus y a Artiodactyla.
} 
lugar, quienes previamente habían hallado material cerámico y un esqueleto humano (que se perdió) cuando pusieron el poste de una tranquera. En las cercanías de esta tranquera, fuera del corral, se excavaron $17 \mathrm{~m}^{2}$. En los primeros $30 \mathrm{~cm}$ se recuperó abundante cerámica, restos faunísticos y carbón en un horizonte húmico fango arenoso. Entre los $35-45 \mathrm{~cm}$ se observa una interface entre el horizonte húmico y los depósitos areno fangosos inferiores, donde se hallaron los dos entierros humanos y huesos humanos aislados.

El análisis del material cerámico de este sitio está aún en proceso. Se contabilizaron alrededor de 5200 fragmentos y se analizaron 587 recuperados en la primera excavación de $3 \mathrm{~m}^{2}$, los cuales permiten observar algunas tendencias iniciales. Al igual que en LDLG1, la cerámica fue cocida mayoritariamente en una atmósfera oxidante y presenta superficies alisadas o pulidas. Sólo en un $5,4 \%$ de los tiestos se observó algún tipo de decoración (i.e. aplicación de pigmento rojo, incisión en sus distintas variantes y modelado), destacándose un asa zoomorfa (probablemente una cabeza de mamífero) y un apéndice en forma de cabeza de ave (psitácido). Si bien se identificaron huellas de alteración, éstas se presentan en menor proporción que en LDLG1, tal es el caso del abradido (superficie interna: 30\%; superficie externa: $24,8 \%$ ) como del agrietamiento (superficie interna: $12,2 \%$ y superficie externa: 11,3\%). Por otro lado, se observaron restos de hollín en un $8,5 \%$ de los fragmentos $(n=50)$, a diferencia de LDLG1 donde sólo el 0,36\% presentaba este tipo de adherencia. Finalmente, no se observaron rasgos de manufactura deficiente.

Se analizaron los 461 restos faunísticos recuperados en LDLG2, de los cuales 354 pudieron ser determinados a algún nivel taxonómico. De la misma manera que en LDLG1, predominan los mamíferos indeterminados (NISP=136). Los mamíferos más representados también son Myocastor coypus (NISP=40), Hydrochoerus hydrochaeris (NISP=13) y Blastocerus dichotomus (NISP= 3), aunque en proporciones menores que en LDLG1. Otra diferencia es la mayor representatividad que muestran los peces Actinopterygii (NISP=91) y Siluriformes (NISP= 46) y la presencia de Mollusca (NISP=19). Los restantes taxa identificados son Ave $(\mathrm{NISP}=4)$, Canidae $(\mathrm{NISP}=1)$ y Artiodactyla (NISP=1).

En cuanto a los entierros humanos recuperados en el sitio, los análisis bioarqueológicos realizados permitieron establecer que el individuo 1 corresponde a un adulto joven masculino, entre 22 y 29 años (estadio 2-4 para sínfisis púbica y fase II para carilla auricular del ilion). Se trata de un esqueleto incompleto en posición decúbito dorsal que incluye la cintura pélvica con los miembros inferiores articulados y que posee el cráneo relocalizado sobre la pelvis. El resto de los elementos óseos estaban ausentes. El entierro presentaba una orientación NorteSur, con las órbitas del cráneo orientadas hacia el Oeste y estaba asociado con tiestos cerámicos, entre los cuales se destaca uno de los apéndices zoomorfos ya mencionados. Fue datado en $570 \pm 43$ años ${ }^{14} \mathrm{C} \mathrm{AP}$ (Tabla 1). En cercanías a este entierro fueron hallados elementos óseos aislados; se trata de un húmero y las tres primeras vértebras cervicales, que corresponderían a un individuo adulto. No se descarta que estos restos pertenezcan al individuo 1. Al realizar un análisis minucioso tanto en los huesos del individuo 1 como en los elementos aislados, no fue encontrado ningún tipo de huellas antrópicas (e.g. marcas de corte).

El entierro del individuo 2 (posiblemente un adulto) es de tipo primario, completo y se encontraba en posición dorsal extendido. Debido a que este esqueleto se hallaba a poca profundidad (entre 35 y $40 \mathrm{~cm}$ ), en un sedimento con raíces y en la entrada de un corral de ganado, todos los restos óseos poseen un estado de preservación malo y están muy fragmentados; es por este motivo que las determinaciones sexo-etarias no pudieron realizarse con precisión. Junto a la parte posterior de la bóveda craneana se encontró una concentración de sedimento con espículas de carbón y restos de ictiofauna. Para este individuo se obtuvo una datación de $590 \pm 46$ años ${ }^{14} \mathrm{C}$ AP (Tabla 1).

Como resultado de los estudios paleopatológicos preliminares que se están desarrollando, se registraron líneas de hipoplasia del esmalte dental en los dos caninos superiores del individuo 1. Al evaluar patologías degenerativas articulares, se observa que este individuo no presenta señales de osteoartrosis en sus articulaciones. Por su parte, en el individuo 2 también se registraron tres dientes del maxilar (incisivo lateral derecho; incisivo lateral y canino izquierdo) con líneas de hipoplasia del esmalte dental. Debido al mal estado de conservación y la alta fragmentación de los huesos de este esqueleto, no pudieron ser evaluadas lesiones de tipo degenerativas.

\section{Discusión}

El sitio LDLG1 muestra una gran extensión del material arqueológico, pero con baja densidad artefactual. La resolución estratigráfica de este sitio arqueológico permite clasificarlo dentro de la categoría "somero" (sensu Zárate et al. 2000/2002) emplazado en una geoforma naturalmente elevada del tipo albardón (esto es, sin incremento antrópico de la altura). Las evidencias arqueológicas se concentran en los primeros $40 \mathrm{~cm}$ del horizonte $A$ que suprayacen a los depósitos areno fangosos a arenosos que caracterizan a estas geoformas naturales. De acuerdo a la propuesta de Politis y Bonomo (2012) sobre los distintos tipos de asentamientos de GoyaMalabrigo, los sitios como LDLG1 se habrían originado por ocupaciones esporádicas y recurrentes. Dicha recurrencia ocupacional debió vincularse a momentos de estabilidad hidrológica de la cuenca, durante momentos medios a bajos del río Paraná, debido a que durante las fases de 
aguas altas el área de emplazamiento del sitio pudo verse afectada por efecto de las inundaciones.

Los estudios botánicos y faunísticos muestran que durante la ocupación del sitio se explotaron recursos faunísticos variados y posiblemente se consumió maíz aunque, como ya se ha expresado, la evidencia no es conclusiva. Los principales recursos aprovechados en el sitio han sido los roedores; principalmente el coipo y, en segundo lugar, el carpincho. El ciervo de los pantanos ocupa un lugar secundario en términos de NISP y NMI, aunque si consideramos el tamaño de este mamífero, probablemente representó un aporte importante a la subsistencia. Otros mamíferos, como los carnívoros, tienen una representación minoritaria en el conjunto pero muestran una amplia diversidad taxonómica y, en algunos casos, claras evidencias de aprovechamiento antrópico. Es interesante destacar la significativa representación de ciervo de los pantanos y la baja frecuencia de peces en comparación con otros sitios del área como Los Tres Cerros 1, donde los cérvidos están virtualmente ausentes y los peces constituyen más del $80 \%$ del conjunto (Bastourre 2014).

A partir de los análisis efectuados es posible comenzar a discutir la historia tafonómica del conjunto arqueofaunístico. Las alteraciones antrópicas registradas y el contexto de los hallazgos permiten proponer a los seres humanos como el principal agente acumulador pero las evidencias de abrasión sedimentaria registradas en muchos de los especímenes óseos probablemente se vinculan a la actividad fluvial. Por ello, considerando el contexto sedimentario de los hallazgos arqueológicos en un albardón sujeto a inundaciones, se torna necesario profundizar en el futuro el estudio de la incidencia del agua, especialmente en relación al desplazamiento de los elementos y su consecuente sesgo en la abundancia anatómica y taxonómica del conjunto. A partir del bajo grado de meteorización de los especímenes óseos, se infiere sin embargo un sepultamiento relativamente rápido del conjunto en los sedimentos aluviales del albardón. Una vez enterrados, la interacción química con los componentes de la matriz sedimentaria generó la tinción de los restos (enmascarando la termoalteración) y la acción de raíces generó trazas sobre la superficie de los huesos y probablemente contribuyó a su movimiento y fragmentación. Asimismo, a partir de las correlaciones efectuadas entre el porcentaje de supervivencia de los especímenes y la DMO, es posible inferir que los procesos de destrucción post-depositacional mediados por la densidad han condicionado la supervivencia diferencial de los huesos, al menos en el caso del perfil esqueletario de Myocastor coypus.

Pese a la compleja historia de formación del sitio, el análisis de las alteraciones antrópicas permite identificar algunas tendencias en relación al procesamiento de los animales. En el caso del coipo, se hallaron en el sitio evidencias de las distintas etapas del procesamiento de las carcasas, que probablemente se transportaron enteras: cuereo, desarticulación (a nivel de hemimandíbula, cuartos traseros y, probablemente, autopodio) y descarne. Si bien la depositación química dificulta relevar la termoalteración y definir un patrón claro de acción térmica, la presencia de este rasgo únicamente en vértebras caudales y falanges permite hipotetizar una relación con el modo de cocción (asado/rescoldo), en tanto las partes terminales del esqueleto son las menos protegidas por el tejido blando cuando éste es expuesto al fuego (Lloveras et al. 2009). Para el carpincho, las huellas de corte indican una secuencia similar de actividades (cuereo, desmembramiento a nivel del fémur, codo y autopodio, y descarne). Es destacable la presencia de fracturas frescas sobre cúbito y tibia con evidencias de aserrado perimetral. Este tipo de fractura cuidadosa, especialmente en un elemento como el cúbito con poco contenido de médula, puede vincularse a la manufactura de instrumentos, como se registró en otro sitio de la región (Bastourre 2014). En comparación con los roedores, los elevados índices de fragmentación de los huesos largos de los artiodáctilos, sumado a los mayores porcentajes de fracturas frescas, permite proponer un procesamiento más intensivo de estos elementos, que posiblemente se vincule al consumo de médula y/o grasa. Esto se ve reforzado por la presencia en el conjunto de numerosas astillas de huesos largos altamente fragmentados (y por ende con poco grado de identificabilidad) que fueron asignados a la categoría de mamífero grande.

Los resultados obtenidos del estudio macroscópico y remontaje del conjunto cerámico recuperado en el sitio LDLG1 permitieron identificar que los materiales cerámicos estuvieron expuestos a agentes erosivos que provocaron un deterioro significativo del material. Las huellas de erosión como el efecto pedestal y el redondeamiento podrían ser el resultado de abrasión sedimentaria, lo que posiblemente haya influido también en la dispersión horizontal de los fragmentos. Las grietas, a su vez, podrían ser el resultado de eventos de hidratación-deshidratación vinculados a la dinámica de sequías-inundaciones típica del área.

Las formas reconstruidas son una primera aproximación a la función de esta alfarería. Considerando sus capacidades generales como contenedores de procesamiento, transporte y/o almacenamiento, el predominio de formas bajas y abiertas, de tamaño mediano a grande (como platos y fuentes) y de cuencos medianos a pequeños indica su uso para el procesamiento y servido de alimentos o líquidos. El estilo y la tecnología cerámica de LDLG1 presentan características similares a las identificadas para la entidad arqueológica Goya-Malabrigo (e.g. recipientes de formas simples, decoración con inciso de surco rítmico y pintura, apéndices modelados zoomorfos y motivos decorativos particulares). 
Algunos fragmentos presentan deficiencias en la manufactura como cocción incompleta, variaciones del espesor de las paredes y bordes y acabados irregulares. Sus diseños decorativos presentan incisiones de trazos poco uniformes (con variaciones en la dirección y la presión ejercida), rebabas (producto de una consistencia demasiado fresca de la pasta) y cruces de las líneas incisas en los vértices; otras incisiones se presentan irregulares y de distribución discontinua. La falta de integración y simetría de los motivos, la imprecisión de los trazos y la cantidad de errores presentes en una misma pieza pueden considerarse como atributos indicadores del grado de habilidad del ceramista. Crown (1999) propone que los diseños ejecutados pobremente, en comparación al resto de las piezas, pueden deberse a una escasa coordinación motriz y/o desarrollo cognitivo, este último vinculado principalmente a la corta edad del artesano. Vidal (2011) plantea que es posible identificar en el registro arqueológico la presencia de aprendices a partir de la observación conjunta de atributos como la variación del grosor de las paredes, la calidad de la pasta, el tratamiento de superficie y la simetría de los diseños. Sin embargo, se debe tener en cuenta, en especial al considerar un posible contexto de aprendizaje, que posiblemente varios individuos hayan contribuido a la fabricación de una misma pieza cerámica, combinando así capacidades individuales y tradiciones culturales (Crown 2007, Vidal y García Roselló 2009). Por lo tanto, los rasgos relacionados a la calidad de la manufactura de algunas piezas cerámicas de LDLG1 pueden estar vinculados tanto a la pericia (aprendices) o a la expeditividad de los alfareros. Esto último sería compatible con la función o jerarquía del asentamiento. Por supuesto, no puede descartarse que ambos factores hayan actuado en conjunto.

Como se observa en la Tabla 4, las edades de $1775 \pm$ 51 y $1775 \pm 47$ años ${ }^{14} \mathrm{C}$ AP obtenidas para el sector 4 de LDLG1 son hasta ahora las más antiguas para la ocupación humana de las islas del Delta Superior del Paraná. La edad que arrojó el sector 3 del mismo sitio, $1236 \pm 43$ años ${ }^{14} \mathrm{C} A P$, es también relativamente alta y está sugiriendo una redundancia de ocupación de esta parte del albardón durante algunos cientos de años. Por lo menos en términos técnico-estilísticos ambas ocupaciones

\begin{tabular}{|c|c|c|c|c|}
\hline Sitio arqueológico & Material datado & $\begin{array}{l}\text { Cantidad de } \\
\text { dataciones }\end{array}$ & $\begin{array}{l}\text { Rango de edad en } \\
{ }^{14} \text { Caños AP }\end{array}$ & Referencias \\
\hline $\begin{array}{c}\text { Cerro Grande de la Isla } \\
\text { Los Marinos }\end{array}$ & Hueso humano & 3 & $\begin{array}{c}460 \pm 50 \text { a } 660 \pm \\
70\end{array}$ & $\begin{array}{c}\text { Kozameh y Brunás } \\
(2011,2013)\end{array}$ \\
\hline Cerro Lote 11 & Materia orgánica & 1 & $490 \pm 60$ & $\begin{array}{l}\text { Bonomo et al. } \\
\text { (2011a) }\end{array}$ \\
\hline Cerro Tapera Vázquez & Carbón vegetal & 2 & $\begin{array}{c}520 \pm 60 a \\
650 \pm 60\end{array}$ & $\begin{array}{l}\text { Bonomo et al. } \\
\text { (2011a) }\end{array}$ \\
\hline Los Tres Cerros 1 & $\begin{array}{l}\text { Carbón vegetal, valva, } \\
\text { hueso humano }\end{array}$ & 21 & $\begin{array}{l}560 \pm 80 \mathrm{a} \\
1227 \pm 45\end{array}$ & Politis et al. (2011) \\
\hline Laguna de Los Gansos 2 & Hueso humano & 2 & $\begin{array}{c}570 \pm 43 a \\
590 \pm 46\end{array}$ & Este trabajo \\
\hline Los Tres Cerros 3 & Materia orgánica & 1 & $600 \pm 60$ & Politis et al. (2011) \\
\hline Cerro El Castaño II & Hueso humano & 1 & $700 \pm 80$ & Cornero (2009) \\
\hline Cerro Farall & Materia orgánica & 1 & $830 \pm 40$ & $\begin{array}{l}\text { Castiñeira et al. } \\
\text { (2014) }\end{array}$ \\
\hline Cerro Pajas Blancas 1 & $\begin{array}{l}\text { Carbón vegetal, } \\
\text { materia orgánica }\end{array}$ & 2 & $\begin{array}{c}640 \pm 60 a \\
650 \pm 70\end{array}$ & $\begin{array}{l}\text { Bonomo et al. } \\
\text { (2011a) }\end{array}$ \\
\hline Cerro Los Cardos & Carbón vegetal & 1 & $906 \pm 38$ & Este trabajo \\
\hline Los Tres Cerros 2 & $\begin{array}{l}\text { Materia orgánica, carbón } \\
\text { vegetal, hueso humano }\end{array}$ & 5 & $\begin{array}{l}920 \pm 40 \mathrm{a} \\
1460 \pm 70\end{array}$ & Politis et al. (2011) \\
\hline Cerro de Diego & Materia orgánica & 1 & $1270 \pm 50$ & Este trabajo \\
\hline Cerro de las Cañas 1 & Materia orgánica & 1 & $970 \pm 60$ & $\begin{array}{l}\text { Castiñeira et al. } \\
\text { (2014) }\end{array}$ \\
\hline Laguna de los Gansos 1 & Hueso fauna & 3 & $\begin{array}{c}1236 \pm 46 a \\
1775 \pm 51\end{array}$ & Este trabajo \\
\hline
\end{tabular}

Tabla 4. Dataciones ${ }^{14} \mathrm{C}$ para el Delta Superior $(n=45)$.

Table 4. Radiocarbon dates obtained for the Upper Delta of the Parana river $(n=45)$. 
parecen haber tenido rasgos similares.

El sitio LDLG2, es un depósito arqueológico con materiales cerámicos, restos faunísticos y entierros humanos de alrededor de 600 años de antigüedad. Estas edades indican una ocupación mucho más reciente, alejadas de las anteriores pero en el mismo albardón aunque en otro sector. Comparte con LDLG1, además de su emplazamiento, la explotación de recursos faunísticos vinculados con ambientes acuáticos, rasgos estilísticos cerámicos y la presencia de los modelados zoomorfos asignados a Goya-Malabrigo. Adicionalmente, es destacable la presencia de entierros humanos con un tratamiento mortuorio complejo, que permiten ampliar el reconocimiento de la variabilidad de los contextos funerarios para el área.

En LDLG 2 se registraron dos claras modalidades de entierro contemporáneas entre sí. Por un lado, un entierro primario en posición dorsal extendido (individuo 2) y por otro, un esqueleto incompleto (tronco ausente) con el cráneo reubicado de manera intencional sobre la pelvis (individuo 1). La diferencia entre ambas modalidades es que en la primera no hay intervención sobre el cuerpo, mientras que en el último caso se puede inferir una gran manipulación del mismo a través de ciertas acciones: desmembramiento, selección de partes y entierro con presencia de tejido blando. Se han identificado entierros similares al del individuo 1 de LDLG2, en sitios del Delta Superior (Cerro Grande de la Isla Los Marinos; Gaspary 1950) e Inferior (El Cerrillo y Arroyo Sarandí; Lothrop 1932). Esta práctica inhumatoria se destaca de los otros tipos de entierros que suelen ser identificados más recurrentemente en la región, como son las inhumaciones primarias y los paquetes funerarios (Cornero 2009; Gaspary 1950; González 1947; Mazza 2015; Scabuzzo et al. 2015). En el caso de Cerro Grande de la Isla Los Marinos (Gaspary 1950; Kozameh y Brunás 2011, 2013), se halló un entierro compuesto por los miembros inferiores y un coxal articulado, con presencia de ocre. El mismo muestra ciertas semejanzas con el del individuo 1 de LDLG2 en cuanto a la presencia de tejido blando al momento de la inhumación; la diferencia radica en que aquí no hay reacomodación de elementos como el cráneo y además se aplicó ocre.

En el caso de El Cerrillo y Arroyo Sarandí, se han identificado a partir de los dibujos del diario de campo y fotografías de Lothrop (Ramos van Raap y Bonomo 2016), esqueletos con gran parte de su cuerpo articulado pero con algunos huesos reubicados (Lothrop 1932: 150). En El Cerrillo, se identificaron: esqueleto $\left(n^{\circ} 10\right)$ en posición decúbito ventral con el cráneo ubicado al lado del codo derecho y con reacomodamiento de los huesos del brazo izquierdo; esqueleto ( $\left.n^{\circ} 4\right)$ extendido en posición decúbito dorsal, con el cráneo sobre la pelvis y los huesos de los miembros superiores acomodados uno al lado del otro y esqueleto incompleto $\left(n^{\circ} 1\right)$ que posee el cráneo sobre las porciones distales de las piernas. Por su parte, en Arroyo Sarandí se observa también un esqueleto incompleto ( $\left.n^{\circ} 19\right)$ con el cráneo sobre la pelvis y otro primario incompleto $\left(n^{\circ} 6\right)$ con el cráneo al lado de la cadera (Ramos van Raap y Bonomo 2016). En conjunto, todas estas evidencias indican que en el Delta del Paraná, durante el Holoceno tardío, coexistieron las inhumaciones primarias junto con otras modalidades que implicaron una gran manipulación y preparación de los cuerpos antes de su entierro final. Este es el caso de los paquetes funerarios y de los esqueletos con gran parte de su cuerpo articulado, pero con algunos huesos reubicados intencionalmente fuera de su posición anatómica.

\section{Conclusiones}

Los resultados de las investigaciones llevadas a cabo en LDLG 1 y 2 permiten abordar algunos aspectos de las sociedades indígenas que ocuparon el Delta Superior del río Paraná durante el Holoceno tardío. Las dataciones de LDLG1 y LDLG2 están dentro del rango cronológico de la entidad arqueológica Goya-Malabrigo. Además, el registro arqueológico recuperado en estos sitios permite inferir varias características presentes en esta entidad, tales como la modalidad de ocupación del espacio insular deltaico, el estilo cerámico, la gran variabilidad de prácticas mortuorias y los componentes de la economía. La localidad fue ocupada por poblaciones asignadas a Goya-Malabrigo, por lo menos durante dos períodos diferentes. LDLG2 fue un asentamiento ocupado hace ca. 600 años ${ }^{14} \mathrm{C}$ AP en donde se llevaron a cabo complejas prácticas mortuorias que incluyeron el desmembramiento, la selección de partes y el reacomodamiento de algunos sectores anatómicos de un mismo individuo. Esto muestra que parte de los rituales mortuorios tuvieron como eje la manipulación de los cuerpos y refleja una tradición compartida entre distintas sociedades tardías del área (por ejemplo, Cerro Grande de la Isla Los Marinos, El Cerrillo, Arroyo Sarandí). LDLG1 representa una sucesión de ocupaciones más cortas sobre un albardón entre ca. 1200 y 1800 años ${ }^{14} \mathrm{C}$ AP, con fines específicos, uno de los cuales habría sido la caza de grandes roedores y de ciervo de los pantanos. Estos asentamientos serían temporarios y de menor jerarquía, respecto a las ocupaciones desarrolladas en estructuras monticulares.

De acuerdo a las edades radiocarbónicas disponibles, la colonización humana del Delta Superior del Paraná, se habría producido en ca. 2000 años ${ }^{14} \mathrm{C}$ AP. Dicha colonización tardía, se vincula con la disponibilidad territorial pos último evento transgresivo del Holoceno. Geográficamente, el área de estudio se emplaza en una de las áreas de mayor vulnerabilidad hidrometeorológica de la cuenca del Paraná. El patrón de asentamiento desarrollado por Goya-Malabrigo denota una variabilidad de estrategias consistentes con dicha vulnerabilidad. Por ello, durante los momentos de estabilidad hidrometeorológica fueron ocupadas las márgenes de los ambientes lóticos y lénticos 
y geoformas naturales elevadas (e.g. albardones y espira de meandros) próximas a las márgenes fluviales activas, donde se desarrollaron estrategias de explotación de recursos específicos como roedores y cérvidos. Este sería el caso de LDLG1. Este patrón, a su vez, se complementa con la construcción de estructuras monticulares, regionalmente conocidas como cerritos (Castiñeira et al. 2013, 2014; Politis y Bonomo 2012). De acuerdo a las evidencias recuperadas en estos, los asentamientos habrían sido de mayor permanencia, incluyendo momentos de inestabilidad hidrometeorológica. Las investigaciones arqueofaunísticas y paleobotánicas desarrolladas en las secuencias monticulares evidencian una intensa explotación de recursos de porte pequeño a mediano, muy abundantes y fácilmente localizables, tales como los peces y los roedores (Bastorurre 2014). Un punto aún sin resolver es si durante la ocupación de LDLG1 se cultivó o consumió maíz, ya que la evidencia no es aún conclusiva. Si se confirmara su registro en el sitio, sería el caso más antiguo de maíz en todo el curso inferior y medio del Paraná, en donde, hasta el momento, la presencia de maíz se remonta a 1089 años ${ }^{14} \mathrm{C}$ AP en el sitio Los Tres Cerros 1 (Sánchez et al. 2013).

Como ya se ha expresado previamente (Politis y Bonomo 2015), desde los inicios del registro de la alfarería GoyaMalabrigo y más tarde de sus rasgos asociados (e.g. construcción de montículos de tierra, hidrocentralidad), se ha planteado su relativa uniformidad y su probable carácter intrusivo en la región (Ceruti 1986: 24; véase también González 1977). LDLG1 provee información para aportar a la discusión del origen de Goya-Malabrigo y para poner a prueba los dos modelos existentes: si es el resultado de un proceso donde predominaron la migración y la etnogénesis o en el que prevalecieron la trasmisión vertical y los procesos adaptativos de las poblaciones locales (cfr. discusión en Politis y Bonomo 2012). Como se ha planteado, es probable que el grupo etno-lingüístico arawak haya tenido un rol importante en la génesis de Goya-Malabrigo (Politis y Bonomo 2012; Serrano 1972). La datación de ca. 1800 años ${ }^{14} \mathrm{C}$ AP de LDLG1 es una de las más antiguas para Goya-Malabrigo y permite proponer la rápida dispersión de esta entidad arqueológica (véase dataciones en Politis y Bonomo 2012: tabla 1 y 2015: figura 13). Esto implica que en un lapso corto de ca. 300 años, los sitios Goya-Malabrigo se distribuyen en un área extensa, desde el norte de Santa Fe (Arroyo Aguilar; Etchegoy 1994; Ruggeroni y Gallagher 2006) hasta el Delta Inferior del Paraná y su llanura aluvial (Túmulo de Campana; Zeballos y Pico 1878; Politis y Bonomo 2015; Mazza 2015), lo que sugiere un proceso de expansión poblacional que involucró pocas generaciones que cubrieron las principales áreas de la distribución geográfica de esta entidad arqueológica (Paraná Medio, Delta Superior, Delta Inferior y Uruguay Inferior). Este proceso sería compatible con el modelo de migración-etnogénesis. Aunque tradicionalmente se ha definido a la etnogénesis como una nueva forma de identidad surgida por cambios históricos y culturales sustanciales, actualmente se la concibe como un modelo dinámico de formación de identidad que involucra tanto el cambio como la continuidad (Voss 2015: 656). Es esta nueva concepción la que provee un marco de referencia más adecuado para abordar el estudio de la génesis de Goya-Malabrigo, ya que reconoce el dinamismo de los procesos identitarios, los que a su vez tienen correlatos con la cultura material. Entre los varios procesos que generan etnogénesis (Hu 2013, Stojanowski 2010, Weik 2014) es probable que el que se aproxime más al origen de Goya-Malabrigo sea el de "fusion and aggregation in which diverse people are joined together in a shared ethnic identity" (Voss 2015: 658). En este contexto teórico es que estamos explorando la historia indígena del Delta del Paraná para entender los procesos sociales de larga duración en la región.

La Plata, 9 abril de 2016

\section{Agradecimientos}

Los autores desean agradecer la colaboración de la familia Jordán, Isidro Ríos, Miguel Reynoso y a todo el personal del Parque Nacional Pre-Delta. Además fue clave la ayuda de Germán Moreira, Ignacio Noriega, Daniel Diederle, Milagros Colobig, Rodrigo Costa Angrizani y Luis Capeletti. Las investigaciones aquí presentadas fueron financiadas con el proyecto "Farming, Mound Building, and Social Complexity in the Upper Delta of the Paraná River" (grant \# 9328-13), National Geographic Society's Committee for Research and Exploration.

\section{Bibliografía}

Andrews, P. 1990. Ow/s, Caves and Fossils. University of Chicago Press, Chicago.

Balfet, H., M. Fauvet-Berthelot y S. Monzón. 1992. Normas para la descripción de vasijas cerámicas. Centro de Estudios Mexicanos y Centroamericanos, México DF.

Bastourre, L. 2014. Estudios arqueofaunísticos en el Delta Superior del Paraná: el sitio Los Tres Cerros 1 (Provincia de Entre Ríos, Argentina). Revista Chilena de Antropología, 30: 109-115.

Behrensmeyer, A. 1978. Taphonomic and Ecologic Information from Bone Weathering. Paleobiology, 4: 150-162.

Bonomo, M., G. Politis y J. C. Castro. 2010. Primeros resultados de las investigaciones arqueológicas en el Delta Superior del Paraná y su contribución al atlas arqueológico de la provincia de Entre Ríos. Folia Histórica del Nordeste, 18: 33-58.

Bonomo, M., G. Politis y C. Gianotti. 2011a. Montículos, jerarquía social y horticultura en las sociedades indígenas del delta del río Paraná (Argentina). Latin American Antiquity, 22(3): 397-333.

Bonomo, M., F. Aceituno Bocanegra, G. Politis y M. L. Pochettino. 2011b. Pre-Hispanic horticulture in the Paraná Delta (Argentina): archaeological and historical evidence. World Archaeology, 43(4): 557-579. 
Buikstra, J. E. y D. H. Ubelaker. 1994. Standards for Data Collection from Human Skeletal Remains. Arkansas Archaeological Survey Research Series $N^{\circ} 44$, Arkansas.

Caggiano, M. A. 1984. Prehistoria del noreste Argentino, sus vinculaciones con la República Oriental del Uruguay y sur de Brasil. Pesquisas, Antropología, 38: 1-109.

Castiñeira, C., A. Blasi, M. Bonomo, G. Politis y E. Apolinaire. 2014. Modificación antrópica del paisaje durante el Holoceno tardío: las construcciones monticulares en el delta superior del río Paraná. Revista de la Asociación Geológica Argentina, 71 (1): 33-47.

Castiñeira, C., A. Blasi, G. Politis, M. Bonomo, L. del Puerto, R. Huarte, J. Carbonari, F. Mari y F. García-Rodríguez. 2013. The origin and construction of pre-Hispanic mounds in the Upper Delta of the Paraná River (Argentina). Archaeological and Anthropological Science, 5: 37-57.

Ceruti, C. N. 1984. Proyecto Investigaciones arqueológicas en el área del Paraná Medio - margen entrerriana. Síntesis de los Avances a Noviembre de 1984. Informe 73 Cod. 721, Agua y Energía Eléctrica - Sociedad del Estado, Paraná.

Ceruti, C. N. 1986. Algo sobre crítica y autocrítica en Arqueología. Revista de Antropología, 1: 19-24.

Ceruti, C. N. 2003. Entidades culturales presentes en la cuenca del Paraná Medio (margen entrerriana). Mundo de Antes, 3: 111-135.

Ceruti, C. N., M. I. González. 2007. Modos de vida vinculados con ambientes acuáticos del Nordeste y Pampa Bonaerense de Argentina. Relaciones de la Sociedad Argentina de Antropología, 33:101-140.

Colobig, M. M., A. Zucol, M. Bonomo y G. Politis. 2014. Estudios arqueobotánicos del sitio Laguna de los Gansos 1 (Delta Superior del río Paraná, Argentina): análisis de microrrestos vegetales en materiales cerámicos. Trabajo presentado en el Taller "Micro Paleoetnobotánica": Relevancia de una Red Interdisciplinaria de Investigaciones en Fitolitos y Almidones, La Paloma, Uruguay.

Convención Nacional de Antropología. 1966. Primera Convención Nacional de Antropología. Primera parte. Córdoba: Facultad de Filosofía y Humanidades, Instituto de Antropología.

Cornero, S. 2009. Apuntes de arqueología de Islas. Sitio El Castaño, Boca de La Milonga, Río Paraná. Anuario de Arqueología, I (1): 153-160.

Crown, P. 1999. Socialization in American Southwest Pottery Decoration. Skibo, J.,G. Feinman, Pottery and People, 25-43, University of Utah Press, Salt Lake City.

Crown, P. 2007. Life Histories of Pots and Potters: Situating the Individual in Archaeology. American Antiquity, 72 (4): 677-690.

Escosteguy, P., Salemme, M. y M. I. González. 2012. Myocastor coypus ("coipo", Rodentia, Mammalia) como recurso en los humedales de la Pampa bonaerense: patrones de explotación. Revista del Museo de Antropología, 5: 13-30.

Escosteguy, P., M. Vigna. 2010. Experimentación en el procesamiento de Myocastor coypus. Berón, M., L. Luna, M. Bonomo, C. Montalvo, C. Aranda y M. Carrera Aizpitarte, Mamül Mapu: pasado y presente desde la arqueología pampeana, Tomo I: 293-307, Editorial Libros del Espinillo, Ayacucho.

Echegoy, C. 1994. Los fechados C14 de Arroyo Aguilar. Arqueología del Paraná 2. Reconquista, Museo Municipal de Arqueología y Paleontología de Reconquista. 31 pp.

Fisher, J. 1995. Bone surface modifications in zooarchaeology. Journal of Archaeological Method and Theory, 2(1): 7-68.

García Roselló, J. y M. Calvo Trías.2006. Análisis de las evidencias macroscópicas de cocción en la cerámica prehispánica: una propuesta de estudio. Mayurqa, 31: 83-112.

Gaspary, F. 1950. Investigaciones Arqueológicas y Antropológicas en un Cerrito de la Isla Los Marinos (Pcia. de Entre Ríos). Publicación del Instituto de Arqueología, Lingüística y Folklore, XXIII: 3-66.

González, A. 1947. Investigaciones arqueológicas en las nacientes del Paraná Pavón. Universidad Nacional de Córdoba, Córdoba.

González, A. 1977. Arte precolombino de la Argentina. Introducción a su historia cultural. Film Ediciones Valero, Buenos Aires.

González de Bonaveri, M. I. y M. M. Frère. 2010. Diseños prehispánicos de la alfarería pampeana. Facultad de Filosofía y Letras, Universidad de Buenos Aires, Buenos Aires.

Ghiani Echenique, N., A. R. Uvietta y R. Gambaro. 2013. Alfarerías tubulares en el noreste de la provincia de Buenos Aires: caracterización y distribución. Revista del Museo de La Plata, Antropología, 13 (87): 229-314.

Gutiérrez, M. 2004. "Análisis Tafonómicos en el área Interserrana (Provincia de Buenos Aires)". Facultad de Ciencias Naturales y Museo, Universidad Nacional de La Plata, Argentina, 533 pp. Tesis Doctoral. La Plata.

Gutiérrez, M. y C. Kaufmann.2007. Criteria for the Identification of Formation Processes in Guanaco (Lama guanicoe). Bone Assemblages in Fluvial-Lacustrine Environments. Journal of Taphonomy, 5 (4):151-176.

Hu, D. 2013. Approaches to the Archaeology of Ethnogenesis: Past and Emergent Perspectives. Journal of Archaeological Research, 21: 371-402.

Joyce, T. A. 1912. South American Archaeology: an Introduction to the Archaeology of the South American Continent with Special Reference to the Early History of Peru. G. P. Putnam's Sons, New York.

Kozameh, L. y O. Brunás. 2011. Paleopatología: paget óseo en un resto prehispánico. Microscopía y datación. Actualizaciones en Osteología, 7 (2): 93-95.

2013. Enfermedad de paget en un individuo prehispánico del delta del Paraná, confirmado por examen histológico y datación radiocarbónica. Cuadernos del Instituto Nacional de Antropología y Pensamiento Latinoamericano, 1 (1): 114-120. 
Lafon, C. R. 1972. El replanteo para la arqueología del nordeste argentino. Antiquitas, 14:1-16.

Lam, Y. M., Xingbin Chen y O. M. Pearson. 1999. Intertaxonomic Variability in Patterns of Bone Density and the Differential Representation of Bovid, Cervid, and Equid Elements in the Archaeological Record. American Antiquity, 64 (2): 343-362.

Lam, Y. M., O. M. Pearson, C. W. Marean y Xingbin Chen. 2003. Bone density studies in zooarchaeology. Journal of Archaeological Science, 30: 1701-1708.

Lista, R. 1878. Les cimentières et paraderos minuanes de la province d'Entre-Rios. Revue d'Anthropologie, 7: 365-368.

Lloveras, L., M. Moreno-García y J. Nadal. 2009. Butchery, Cooking and Human Consumption Marks on Rabbit (Oryctolagus cuniculus) Bones: An Experimental Study. Journal of Taphonomy, 7 (2-3): 179-201.

Loponte, D. 2008. Arqueología del Humedal del Paraná Inferior (Bajíos Ribereños Meridionales). Asociación Amigos del Instituto Nacional de Antropología y Pensamiento Latinoamericano, Buenos Aires.

Lothrop, S. 1932. Indians of the Paraná Delta, Argentina. Annals of the New York Academy of Science, 32: 77-232.

Lyman, R. L. 1984. Bone density and differential survivorship of fossil clases. Journal of Anthropological Archaeology, 3: 259-299.

Lyman, R. 1994. Vertebrate Taphonomy. Cambridge University Press, Cambridge.

Lyman, R. 2008. Quantitative Paleozoology. Cambridge University Press, Cambridge.

Lyman, R. L., L.E. Houghton y A. L. Chambers. 1992. The effect of structural density on marmot skeletal part representation in archaeological sites. Journal of Archaeological Science, 19: 557-573.

Malvárez, A. 1999. El Delta del Río Paraná como mosaico de humedales. Malvárez, A. I., Tópicos sobre humedales subtropicales y templados de Sudamérica, 1: 35-53, Oficina Regional de Ciencia y Tecnología de la UNESCO para América Latina y el Caribe - ORCYT, Montevideo.

Mazza, B. 2015. Colecciones antiguas, datos nuevos: Primeros resultados del análisis de las colecciones bioarqueológicas del Humedal del Paraná Inferior. Revista del Museo de Antropología 8(1), 133-146.

Mengoni Goñalons, G. L. 1999. Cazadores de Guanacos de la Estepa Patagónica. Sociedad Argentina de Antropología, Buenos Aires.

Mengoni Goñalons, G. L. 2010. Zooarqueología en la práctica. Algunos temas metodológicos. Xama, 19: 83-113.

Orton, C., P. Tyers y A. Vince. 1997. La Cerámica en Arqueología. Barcelona: Crítica.

Pavao, B. y P. W. Stahl. 1999. Structural Density Assays of Leporid
Skeletal Elements with Implications for Taphonomic, Actualistic and Archaeological Research. Journal of Archaeological Science, 26: 53-66.

Politis, G., M. Bonomo, C. Castiñeira y A. Blasi. 2011. Archaeology of the Upper Delta of the Paraná River (Argentina): Mound Construction and Anthropic Landscapes in the Los Tres Cerros Locality. Quaternary International, 245: 74-88.

Politis, G. y M. Bonomo. 2012. La entidad arqueológica GoyaMalabrigo (Ríos Paraná y Uruguay) y su filiación Arawak. Boletín de la Sociedade de Arqueologia Brasileira, 25(1):10-46.

2015. Una revisión del Túmulo de Campana. Relaciones de la Sociedad Argentina de Antropología, XL (1): 149-181.

Ramos van Raap, M. A. y M. Bonomo. 2016 Nuevos estudios de la colección bioarqueológica de los sitios Arroyo Malo, El Cerrillo y Arroyo Sarandí (Delta del Paraná). Intersecciones en Antropología (vol. especial 3): 71-82.

Rice, P. M. 1987. Pottery Analysis: A Sourcebook. Chicago: University of Chicago Press.

Rodríguez, J. A. 1999. Síntesis e integración cultural en la arqueología del Nordeste Argentino: evaluación de su evolución. Volumen en Honor de A.R. González, Universidad de Buenos Aires, Buenos Aires.

Ruggeroni, D. y E. Gallagher. 2006. Historia de la fundación de Reconquista. Museo Municipalidad de Reconquista, Secretaría de Cultura y Educación, Reconquista.

Rye, O. S. 1981. Pottery Technology: Principles and Reconstruction. Taraxacum, Washington D.C.

Sánchez, J. O., M. M. Colobig, A. F. Zucol, G. G. Politis, M. Bonomo y C. Castiñeira. 2013. Primeros resultados sobre el uso prehispánico de los vegetales en el sitio arqueológico Los Tres Cerros 1 (Victoria, Entre Ríos, Argentina): análisis del registro biosilíceo. Darwiniana, nueva serie 1(2): 201-219.

Sanhueza Riquelme, L. 1998. Antecedentes y proposición metodológica para el estudio de huellas de alteración en cerámica. Conserva, 2: 69-79.

Scabuzzo, C., M. A. Ramos van Raap; M. Bonomo y G. Politis. 2015. Estudios bioarqueológicos en el sitio Los Tres Cerros 1 (Delta Superior del río Paraná, Entre Ríos, Argentina). Boletim do Museu Paraense Emílio Goeldi, Ciências Humanas 10 (2): 487-518.

Schiffer, M. B. y J. M. Skibo. 1989. A Provisional Theory of Ceramic Abrasion. American Anthropologist, New Series 91 (1): 101-115.

Schmitz, P. I., C. N. Ceruti, A. R. González y A. Rizzo. 1972. Investigaciones arqueológicas en la zona de Goya (Corrientes), Argentina. Dédalo, VIII (15): 7-121.

Serrano, A. 1972. Líneas fundamentales de la Arqueología del Litoral (una tentativa de periodización). Instituto de Antropología de la Universidad Nacional de Córdoba, Córdoba.

Stojanowski, C. M. 2010. Bioarchaeology of Ethnogenesis in 
the Colonial Southeast. Gainesville: University Press of Florida.

Torres, L. M. 1907. Arqueología de la cuenca del río Paraná. Revista del Museo de La Plata, XIV: 53-122.

Ubelaker, D. 1999. Human Skeletal Remains. Taraxacum, Washington.

Vidal, A. y J. García Roselló. 2009. "Dime cómo lo haces": Una visión etnoarqueológica de las estrategias de aprendizaje de alfarería tradicional. Arqueoweb: Revista sobre Arqueología en Internet, 12.

Vidal, A. 2011. Para aprender no hay edad: irregularidades frecuentes en la cerámica realizada por aprendices adultos. Moreano, A., J. Baena Preysler y D. García González, La Investigación Experimental aplicada a la Arqueología, 393-399. Universidad de Granada, Ronda.

Vignati, M. A. 1942. Alfarerías tubulares de la región de Punta Lara. Relaciones de la Sociedad Argentina de Antropología, I: 60-63.

Voss, B. L. 2015. What's New? Rethinking Ethnogenesis in the Archaeology of Colonialism. American Antiquity, 80 (4): 655-670.
Waldron, T. 2009. Paleopathology. Cambridge University Press, New York.

Weik, T. M. 2014. The Archaeology of Ethnogenesis. Annual Review of Anthropology, 43: 291-305.

White, T. y P. Folkens. 2005. The Human Bones Manual. Elsevier Academic Press, Londres.

Winter, C. P., M. Fagundes y S. C. Rodrigues. 2010. Una aproximación tafonómica al análisis arqueológico del material cerámico: Caso experimental sitio São Lourenço 1, Municipio de Ituiutaba (MG). Revista UnG - Geociências, 9 (1): 14-33.

Willey, G. 1971. An Introduction to American Archaeology. Volume Two: South America. Prentice-Hall, New Jersey.

Zárate, M., M. González, N. Flegenheimer y C. Bayón. 20002002. Sitios arqueológicos someros: El concepto de sitio en estratigrafía y sitio de superficie. Cuadernos del Instituto Nacional de Antropología y Pensamiento Latinoamericano, 19: 635-653.

Zeballos, E. y P. Pico. 1878. Informe sobre el túmulo prehistórico de Campana. Anales de la Sociedad Científica Argentina, 6: 244-260. 